\title{
LIBERDADE, FELICIDADE E ESTADO DE BEM-ESTAR SOCIAL: UMA REFLEXÃO A PARTIR DE THOMAS HOBBES E AMARTYA SEN
}

\section{Gerardo Clésio Maia Arruda ${ }^{1}$}

\section{RESUMO}

Felicidade é apreendida como uma essencialidade humana, condicionada à ideia de liberdade, uma vez que só o homem livre pode dispender esforços que lhe permitam alcançar as coisas imaginadas como proporcionadoras de prazer. Com base nas reflexões de Thomas Hobbes e Amartya Sen, pensadores que se encontram nos extremos da era moderna, conclui-se que o Estado de bem-estar social constitui o tipo de sociedade política ideal para disponibilizar as condições necessárias para efetivar as garantias mínimas a uma existência digna e, por conseguinte, para a realização da felicidade humana.

Palavras-chave: Estado de bem-estar; Garantia; Segurança; Liberdade; Felicidade.

\section{FREEDOM, HAPINESS AND WELFARE STATE: A REFLECTION TROUGH THOMAS HOBBES AND AMARTYA SEN}

\begin{abstract}
Hapiness is learned as a human essenciality, linked to the idea of liberty, that so, the free man can only focuse his efforts that allows himself to fullfill the imaginaded goals as capable of giving pleasure. Based in Thomas Hobbes reflections as well Amartya Sen, thinkers that found themselves in the extremes of modern era, it is concluded that the Welfare State constitutes the tipe of ideal political society to be able to make possible the basic conditions that can turn effective the garanties to a dignify existence, and therefor, to the realization of the human hapiness.
\end{abstract}

Key-Words: Welfare State; Garantee; Security; Freedom; Hapiness

\section{INTRODUÇÃO}

A felicidade é um desejo gravado no âmago do indivíduo, que, no objetivo de alcançá-la, precisa empregar esforços para adquirir os meios que o conduza na sua direção. Trata-se de uma condição que pode se concretizar em bens materiais e imateriais. Para os filósofos clássicos, como se depreende do pensamento de Aristóteles, a felicidade se trata de um bem último que produz a auto realização, o desejo atendido em sua plenitude, por isto todos os outros bens adquiridos são meios para atingi-lo. Vê-se, então, que a felicidade

\footnotetext{
${ }^{1}$ Professor do Programa de Mestrado em Direito do Centro Universitário Christus (UNICHRISTUS) e Professor Titular da Universidade de Fortaleza (UNIFOR). Doutor e Mestre em Sociologia, Especialista em Geografia e Graduado em Ciências Econômicas.
} 
se encontra hermeticamente vinculada à utilidade, de sorte que a representação de uma pressupõe a da outra.

Presente em culturas assemelhadas e dessemelhadas, a felicidade se manifesta de infinitas maneiras, o que torna impossível uma delimitação de tipos. Trata-se de um fim explicitado nos espíritos desde tempos imemoriais, que subsiste no presente e se tem como dado sua existência no futuro. Enfim, é uma condição humana essencial, que conduz a seguinte afirmação: viver é uma busca incessante da felicidade. Entretanto, é característica imanente a este tema a divergência quanto às proposições demonstradas como sendo as adequadas à sua efetivação, de tal maneira que são inumeráveis as formulações presentes no campo filosófico e nas ciências sociais.

Ao se referenciar a felicidade entre os clássicos, em princípio, é preciso anotar a crença de que o agir virtuoso não está condicionado à interpretação de um dever, de uma adequação do comportamento a obrigações pactuadas. Nas palavras de Caillé et all (2004), não se encontrava no horizonte do pensamento dos antigos a ideia de um ordenamento impositivo a partir de instância superior fundada com esse objetivo. A obediência à "lei da cidade", como um aspecto a ser observado pelo homem virtuoso, foi o recorte realizado pelo pensamento moderno, subsequente às elaborações propugnadas no medievo, que influiu na fundamentação do entendimento da virtude moderna como sendo uma disposição à obediência de leis morais.

Os filósofos gregos e romanos acreditavam que era no interior do homem e não no exterior onde se localizava o fundamento da essência da ética, que é derivada da relação entre a virtude e a felicidade. Uma vez que a virtude se trata de uma qualidade do homem para fazer com excelência aquilo para o qual está originalmente condicionado, tem-se que esta predisposição natural é o alicerce sobre o qual se erige o regramento de seu comportamento. O homem deve, então, orientar o seu agir para a tendência que se encontra no seu interior, e não balizar o seu comportamento por um delineamento elaborado fora dele mesmo, ou seja, ele deve procurar desenvolver aquilo que se encontra predisposto em si ou conduzi-lo para as coisas que proporcionem seu desenvolvimento. Estes argumentos permitem a seguinte formulação propugnada por Caillé et all (2004): a felicidade é o bem supremo edificado na excelência da realização daquilo que se encontra em si e que possibilita alcançar todos os outros bens desejados e descartar todos aqueles que lhe podem obstar. 
Ao refletir sobre a felicidade e o sentido da vida, Stork e Echevarría (2005) sugerem para este tema complexo uma abordagem que adote de forma complementar a perspectiva externa, objetiva, a partir de fora, simultaneamente, à perspectiva interna, circunscrita ao interior dos indivíduos. Isto porque a felicidade não é parcial e, portanto, pressupõe o desenvolvimento pleno de todas as dimensões humanas. A alma harmoniosa seria resultado da posse de algo objetivado, que, enquanto fim último desejado, tornar-se-ia capaz de aplacar os afãs, as tendências e os afetos, e assim unificados constituem-se em elementos orientadores e significantes das ações. Salientam ainda os autores que uma condição fundamental para aspirar a felicidade é não ser miserável, pois faz-se necessário um mínimo de bem-estar.

Referenciado neste entendimento acerca da felicidade, busca-se aqui salientar o que poderia prover todos os indivíduos das condições mínimas de sobrevivência, que lhe assegurasse a possibilidade de idealizar e de perseguir a realização do que foi idealizado, que o deixasse livre de ameaças e assegurasse o exercício das ações necessárias. Enfim, procura-se delinear, com base no pensamento clássico e no contemporâneo, a sistematização de proposições fundamentais para o engendramento, a universalização e a garantia da segurança e da autonomia, elementos que possibilitariam aos indivíduos colocar em funcionamento seus esforços da melhor maneira imaginada para alcançar os bens que o permitam caminhar na direção do bem último idealizado.

Neste artigo, apoiado nos pensamentos de Thomas Hobbes e Amartya Sen, buscase trazer à lume a essencialidade do Estado como condição sine-qua-non para a universalização de condições geradoras de segurança e autonomia; embora separados secularmente no concernente à temporalidade, defende-se aqui que o pensamento destes teóricos, a despeito de se encontrarem nos extremos da modernidade, possuem uma complementaridade mister quando se pensa a felicidade como imanente ao ser humano, bem como na constatação de que se encontra aí o fundamento orientador do processo civilizatório.

O terror da violência produzida nas guerras sanguinárias de seu tempo é marca indelével na psique de Thomas Hobbes, e que exerceu forte influência em sua teorização do absolutismo. Eis a causa que o leva a opor-se a Aristóteles, que exaltava a filosofia como saber a ser buscado por um amor puro, conhecimento que se devia realizar como ação humana destituída de interesses ou vantagens. Hobbes contrapôs-se a esta concepção 
ao afirmar a existência de uma utilidade concreta da filosofia, a saber, que se trata de um conhecimento que, ao adotar normas científicas à moral e à política, se notabilizava como instrumento capaz de evitar as guerras e as calamidades, a partir da fundamentação de ações construtoras e mantenedoras da paz. (REALE e ANTISERI, 2005).

Foram estes pressupostos, presentes na estrutura teórica de Hobbes, que induziram a distingui-lo, quando da construção do objetivo deste artigo. Noutras palavras, a opção por Hobbes se deu em virtude da defesa peremptória do Estado como ente natural para o exercício da garantia universalizada da segurança, elemento basilar para que a felicidade seja um desejo efetivamente realizável.

O economista Amarthya Sen, laureado com o Nobel, vivenciou a grande fome de Bengala em 1943. Evento este que lhe marcou profundamente na juventude e que o levou a procurar demonstrar suas causas. Concluiu o autor que não se encontrava nos mecanismos de funcionamento do mercado, mas na estrutura e na dinâmica política imprimida pelo imperialismo Inglês, politicamente excludente e não democrático, a causa primeira que levou muitos a morrerem de fome ao lado de grandes quantidades de comidas estocadas. Sen elaborou uma estrutura de pensamento que ultrapassou os estreitos limites da análise econômica centrada na racionalização do egoísmo, e produziu estudos balizados também por considerações éticas modeladoras do julgamento humano. Enfim, compreende as questões culturais e as situações de classes sociais, simultaneamente, como elementos chaves para as escolhas individuais.

Vê-se nas reflexões do economista que a liberdade e as capacitações dos indivíduos são vistas como questões fundamentais para o desenvolvimento. O Estado aparece em seu pensamento como garantidor das condições de liberdade, portanto, como ente capaz de dotar os indivíduos da possibilidade de realizar sua capacitação e, por conseguinte, de proporcionar as bases para seu desenvolvimento e bem-estar.

\section{Thomas Hobbes: poder e felicidade}

As posições concernentes à relação felicidade e utilidade, segundo Caillé et all (2004), compreendem desde uma separação radical, em que a felicidade é percebida como possível somente se se verifica a renúncia plena da utilidade, uma vez que, tendo esta última como soberana, se tende a privilegiar a vantagem natural dos indivíduos. A este olhar concernente à felicidade como determinação de uma ordem sobrenatural, contrapõe- 
se a reflexão que vislumbra a possibilidade da felicidade como decorrência de sua assimilação pela utilidade, de tal maneira que só por intermédio da utilidade tornar-se-ia possível a felicidade, quer seja no plano natural ou no sobrenatural.

Caillé et all (2004) observa que, a partir do século XVII, a utilidade foi associada ao interesse, mas de modo diferente da forma adotada na Antiguidade romana, quando se discernia o interesse público ou interesse de Estado do interesse usurário. Isto porque, com as primeiras elaborações filosóficas cristãs, o termo interesse passou a ser associado ao seu aspecto negativo, ou seja, ao empréstimo usurário visando ao ganho financeiro pessoal. $\mathrm{O}$ interesse observado desta perspectiva, enquanto vantagem material, ganhou alargada dimensão e tornou-se pensamento dominante. Percebido, então, como vantagens pessoais de toda ordem, colocava em cheque a noção de coesão da comunidade moral e política. Desta forma, o interesse se contrapunha à noção clássica do bem comum e da utilidade pública.

Salientado, principalmente, sob o enfoque dos ganhos materiais e das vantagens pessoais, e por estar o interesse assim definido e hermeticamente vinculado ao termo utilidade, viu-se enfraquecida a posição que defendia a utilidade como um momento necessário para se alcançar a felicidade. Isto levou o pensamento filosófico, de maneira mais evidente nos séculos XVII e XVIII, a racionalmente discriminar o conteúdo da utilidade e demonstrar de que forma poder-se-ia ser possível a sua identificação com a felicidade. Caillé et all (2004, p. 268) afirma que a busca por demonstrar a existência de nexos entre a utilidade, a virtude e a felicidade exprimiu uma "versão propriamente ética, presente em todos os filósofos racionalistas do século XVII, e a versão política, que se iria valer da via contratual de Hobbes a Locke".

Como assevera Foisneau (2004), Hobbes esboça uma teoria da felicidade fundada na compreensão de que o indivíduo está fadado a uma eterna busca pela potência. Desta assertiva emerge a necessidade de descrever os fatores que ocasionam este movimento. $\mathrm{E}$ no procedimento do exercício de demonstração, Hobbes delineia uma definição mecanicista que distingue o sujeito que experimenta o prazer do objeto que proporciona a sensação prazerosa. Para tanto, sentencia que os termos satisfação, contentamento e prazer são estados que se realizam a partir de um movimento na região do coração; entretanto, compreende que tais sensações não remetem à interioridade do sujeito que as experimenta, ao contrário, nascem de objetos exteriores e se prolongam no sujeito sensitivo. 
Arruda e Teixeira (2015), ao interpretar a discussão de Hobbes acerca do surgimento dos pensamentos, apontam que é no processo relacional do homem com o que lhe é estranho que se origina o mecanismo que possibilita significá-los; ou seja, a maciez ou a aspereza de um objeto, por exemplo, é uma qualidade que não é intrínseca ao objeto e nem ao homem que lhe toca, uma vez que resulta da construção imagética do homem a partir de sua capacidade sensitiva. Com base nestas assertivas, os autores interpretam, com Hobbes, que o sentimento humano delineia um movimento que se dá a partir da pressão dos objetos sobre os órgãos dos sentidos, portanto, o sentimento se constrói com base no reflexo dos objetos no interior dos indivíduos, em que se dá a constituição da imagem, ilusão ou idealização.

Nesta mesma linha de raciocínio, Reale e Antiseri (2005) asseveram que a existência das coisas é ocasionada pelo movimento. Com esta afirmação sustentam que Hobbes alicerça, nesta premissa, a lógica de sua estrutura de pensamento, de tal maneira que o seu raciocínio é sempre baseado no elemento corpo e no elemento movimento. A forma como ele explica os processos cognitivos também seguem este princípio, o que pode ser observado na constatação de que a sensação decorre do movimento iniciado pelo sujeito sensitivo que contata os objetos, e que, logo em seguida, reage realizando outro movimento que finda na elaboração de uma imagem ou representação do objeto contatado.

Neste sentido, como afirmam Arruda e Teixeira (2015), os pensamentos que distinguem as proposições afirmativas ou negativas é o que se denomina de entendimento. Numa palavra, o entendimento se origina no cerne do processo da imaginação, que, por sua vez, só se realiza em função da pressão dos objetos externos sobre os órgãos dos sentidos, o que nos leva à sentença de que o entendimento do homem é determinado na sua relação com os objetos que lhes são estranhos. Reale e Antiseri (2005) sintetizam esta discussão na afirmação de que os pensamentos são representações ou aparências que estão fora dos indivíduos, portanto, o sentido atribuído às coisas, o pensamento são uma concepção elaborada com base nos órgãos sensitivos. Por isto, a definição não expressa a essência das coisas, mas aquilo que se concebe apoiado na experiência.

Nesta concepção de movimento, assenta-se a explicação do mecanismo de elaboração de todos os sentimentos, seja de prazer ou dor, seja de amor ou ódio. Como explicita Foisneau (2004), o amor se trata da relação que une o agente ao objeto de prazer; enquanto apetite ou desejo é denominado por Hobbes como aquilo que impulsiona o 
agente para alcançar o objeto que origina o prazer. Assim, identifica no desejo o princípio gerador do movimento animal e da ação humana. De sorte que o que se denomina de prazer trata-se, na verdade, do movimento que antecede e favorece o movimento vital do agente.

As paixões, o amor e o ódio, esclarecem Arruda e Teixeira (2015, p. 323), derivamse no pensamento de Hobbes de um movimento que envolve a imaginação. Em princípio, "o ato de mover-se, andar, gesticular e falar, demanda primeiramente um pensamento que indique o que, como e para onde." Eis o que leva a imaginação para a base condicionadora de todos os movimentos voluntários. Esses movimentos que ocorrem "no interior do corpo do homem, antes de se manifestarem no andar, na fala e outras ações visíveis, chama-se geralmente esforço.” (HOBBES, 1979, p. 32).

Do entendimento do movimento na direção dos objetos causadores do prazer como fundamento da ação humana, Hobbes deriva a teoria da utilidade sustentada no subjetivismo dos valores. Com efeito, identifica no homem uma atividade de avaliação; ou seja, esclarece que o homem denomina de bom aquilo que lhe proporciona prazer, já o que causa desprazer é denominado de mau. Encerram-se nos movimentos de aproximação e de afastamento daquilo que causa prazer e desprazer o princípio de ação e, simultaneamente, o princípio de avaliação dos objetos.

O papel de avaliador das coisas é, assim, geral e extensivo a todos os indivíduos. Tem-se, então, que o homem é exclusivamente o avaliador de todas as coisas, o que substancia a teoria hobbesiana de subjetivismo dos valores, além do que todos os homens são avaliadores, não sendo considerado o fato de ser ou não erudito ou de sua posição na estrutura social. Sendo assim, as individualidades são constituídas num processo que vai se formando com base na agregação de elementos que vão distinguindo uns em relação aos outros, mas que sofre influência das avaliações realizadas, em virtude de também contribuir para a particularização das individualidades. Vê-se aí que Hobbes se confronta com o pensamento clássico que assente com a ideia da existência de um bem absoluto, uma vez que considera em sua reflexão que o sentido presente nos termos bom e mau são compreendidos com relação à pessoa que as emprega, pois cada um se distingue dos demais em sua subjetividade particular.

Para Hobbes (1979, p. 33), entende-se o que é bom ou mau a partir "da pessoa de cada um (quando não há Estado) ou então (num Estado) da pessoa que representa cada um; 
ou também de um árbitro ou juiz que pessoas discordantes possam instituir por consentimento, concordando que sua sentença seja aceita como regra". Enfim, como o bem tem o seu sentido elaborado a partir do indivíduo que avalia e, por sua vez, como o indivíduo tende a avaliar o que é bom aquilo que lhe é útil, deriva-se daí uma relação de reciprocidade entre a utilidade e a felicidade.

Esta perspectiva da felicidade em Hobbes, leva Foisneau (2004) a asseverar aproximações e diferenças nos pensamentos de Aristóteles e Hobbes. Para este último, se o fim alcançado de fato proporciona o prazer anteriormente imaginado é porque tal fim fora julgado como um bem, portanto, aquilo que é considerado bem e o fim que se deseja alcançar são um só. Tal identidade entre bem e fim é também observada em Aristóteles; porém, há uma distinção quanto à compreensão de ambos acerca da hierarquização dos fins, quanto a ser próximo ou longínquo. A ética clássica valoriza os fins longínquos em detrimento dos fins próximos; enquanto Hobbes, porque se alicerça na teoria do desejo, o que torna o homem não mais orientado por um fim real, mas sim por uma avaliação que discerne os objetos que podem proporcionar satisfação, o fim passa a ser visto como sendo uma projeção subjetiva num mundo de corpos em movimento, o que torna esta projeção sempre cambiável. Enfim, o desejo visto como base no princípio de ação e de valorização leva Hobbes a relevar os fins próximos e, por conseguinte, a transformar a moral espontânea do homem numa moral da utilidade, de tal modo que somos impulsionados a buscar o que queremos como meio para alcançar um fim distante.

Hobbes classifica como sendo vãs, de acordo com Foisneau (2004, p. 303), "as coisas que não servem para nenhum proveito. Nessa perspectiva, pode se compreender o utilitarismo como um protesto, em nome dos fins mais próximos, contra as exigências dos fins últimos do homem." Ao valorizar os fins próximos e reduzir a nada os fins últimos, altera-se também a noção de felicidade, uma vez que como não há um fim último que aplaque o desejo, o contentamento será sempre parcial e não se concretiza na posse indefinida de um bem. Arruda e Teixeira (2015) salientam ainda que a felicidade resulta do desejo satisfeito, por isto o homem se vê diante da necessidade de permanentemente desejar, o que lhe aprisiona num movimento sem fim. Tal pressuposto leva Hobbes a concluir que há no homem uma tendência infinita para a aquisição daquilo que ele pensa como sendo bom, de sorte que o desejo não se esgota ao alcançar o objeto fundador. Russell (1969, p. 73), reafirma esta tese quando pondera que "a felicidade implica 
progresso contínuo; consiste em prosperar, não em ter prosperado; não existe a felicidade estática - excetuando-se, naturalmente, as felicidades do céu, que ficam além de nossa compreensão."

Enfim, como esclarece Foisneau (2004), a felicidade se encontra na busca infinita de meios para aplacar o desejo, que se traduz numa procura permanente de potência. Isto explica porque, no mundo moderno, a demanda por poder tenha substituído a forma antiga que mirava a sabedoria por uma forma nova, em que a felicidade é alcançada quando se consuma o desejo permanente de se conquistar mais poder. Dockès (2017) chama a atenção que, para o entendimento preciso da importância da noção de poder, faz-se necessário lembrar a concepção hobbesiana de que são os sentimentos que estruturam os homens, portanto, que seu espírito, sua inteligência, se desenvolvem na medida mesma de suas paixões. Põe-se, então, uma questão-chave: quais são as paixões que produzem as diferenças de inteligência entre os homens?

Dockès (2017), responde esta indagação levantada por ele mesmo, afirmando que os fatores que desafiam e promovem o desenvolvimento da inteligência é o desejo de poder, de riqueza, de conhecimento e de honra, pois são estes elementos que animam a imaginação e aprimoram a capacidade de julgamento. Constituem-se, em última instância, em formas de poder e meios de se acrescer de mais poder, portanto, em instrumentos garantidores e mantenedores daquilo que possibilita a obtenção de prazeres. O poder é, então, definido por Hobbes como algo que se constitui a partir da aquisição dos meios que possibilitam alcançar os bens desejados. Mais especificamente discrimina o poder natural como formado pelas faculdades do corpo e do espírito, como a força, a beleza, a prudência e a eloquência; já as disposições adquiridas por decorrência do poder natural ou do acaso, como riqueza, reputação e amigos, denomina de poder instrumental.

Em resumo, a felicidade implica na necessidade de um progresso contínuo, pois se dá com a aquisição dos bens que proporcionam prazer, o que leva os homens a permanentemente porem-se em marcha para a aquisição de sempre mais poder, o que pode ser traduzido como um esforço para a manutenção da posse dos meios que lhe proporcionam alcançar o que se deseja. No cerne deste processo o homem procura, por conseguinte, distinguir-se uns dos outros; uma vez que, como detalha Dockès (2017, p. 4), num "mundo conflituoso, somente o poder proporciona esta dupla satisfação: os bens em si mesmo e a distinção que permitem as diferenças de fortuna". 
Esta satisfação que os homens intentam para si não é momentânea, na verdade, procuram garantir sua posse no futuro, no transcurso de sua vida. Com base neste entendimento, Dockès (2017) afirma que a busca permanente não está direcionada para alcançar um prazer extremo, nem majestoso e nem exíguo, mas que possibilite ao agente assegurar uma margem sempre superior de poder em relação ao já apropriado. Isto funciona tanto como uma estratégia para garantir a posse de seus bens como a integridade de sua vida, em virtude da ameaça potencial de outros. Eis aí a causa fundante do movimento que impulsiona o indivíduo para sempre querer se acrescer de poder: a necessidade de proteção. Assim, demonstra-se que a existência e a permanência da felicidade são diretamente proporcionais à capacidade de alargar sempre mais poder.

Pierre Dockès (2017) segue em sua reflexão explicitando que, além de se acrescer por intermédio da procura constante, o poder se amplia também quando do seu exercício. A acumulação suscitada no pensamento hobbesiano difere do sentido presente em Adam Smith (1981) e Karl Marx (1987), uma vez que não se reduz somente a acumulação de mercadorias, bem como a acumulação de riqueza não é necessariamente o tipo perseguido. Em suma, os agentes estão na análise de Hobbes imersos numa procura permanente de mais poder e de fazê-lo se acrescer exercitando-o, assim sendo, buscando assegurarem-se de satisfação no aqui e agora e no futuro.

A análise hobbesiana de poder traz no cerne de seus nexos e demonstração o impedimento do seu desenvolvimento no estado de natureza. Isto porque a coordenação descentralizada não é capaz de impor um respeito generalizado dos homens em relação a todos os outros como pode ocorrer quando da existência de um poder comum. A inexistência desta condição limitadora permitiria aos homens fazer valer, uns sobre os outros, maneiras de efetivar seus desejos de mais poder. E como todo poder ganho possibilita acréscimo de poder, destituídos de impedimentos, recairia sobre todos a ameaça de ter seu poder tomado de assalto, uma vez que o poder do outro pode se constituir um meio de se obter mais poder, mais rendimento de poder, portanto, mais felicidade.

A discussão até aqui realizada permite afirmar que os sentimentos construídos com base na existência dos movimentos explicitados por Hobbes findam por ocasionar um cerceamento da liberdade. Esta assertiva se assenta no pressuposto que dá sustentação, no pensamento hobesiano, à construção da sociedade e do Estado; pressuposto este que identifica como sendo o bem originário, a vida e sua conservação, que tem como seu 
extremo o mal primeiro, a morte. Com efeito, por intermédio do consenso, os homens passaram a convencionar que todos têm direitos a compartilhar os direitos requeridos individualmente, o que deu origem ao princípio da partilha e o da justiça. Numa palavra, o Estado se constitui no maior de todos os poderes humanos, dado a sua constituição a partir da reunião, por consentimento, de vários poderes individuais, formando assim um único poder que dispõe de todos os poderes submetidos à sua vontade.

\section{Amartya Sen: liberdade e felicidade}

Para Amarthya Sen (1992), a economia não é uma ciência exata, pura e imune às influências ideológicas, dada suas interfaces com as ações políticas e as questões éticas. Sua pesquisa sobre Adam Smith o conduziu a especular sobre a possibilidade de conciliação do "egoísmo racional", fundamental para os neoliberais, com o que o próprio Smith explicita acerca do homem na obra A teoria dos sentimentos morais, onde o homem é apreendido como cidadão que sobrepõe a comunidade humana ao seu interesse particular.

Apesar de reconhecer como válida a interpretação, hegemônica no século XIX, de que Adam Smith relevava o mercado enquanto fonte de eficácia da produção, que por isto fazia-se necessária a superação das instituições características do feudalismo, Sen (1992) contrapõe ao exclusivismo desta vertente interpretativa do pensamento smithiano o fato de que o economista inglês não enxergava o mercado como absoluto e presente em todas as esferas da vida social. Uma análise que induz à constatação de que o homem não é fundamentalmente um "egoísta racional", interessado somente na maximização do seu bem-estar. Assevera Sen (1992, p. 15) que os equívocos dos interpretes de Adam Smith quanto "aos mercados, bem como o desprezo de sua análise ética dos sentimentos e dos comportamentos, são coerentes com o distanciamento entre a economia e a ética no desenvolvimento da economia moderna."

De acordo com Sen (1992), é possível asseverar que o economista liberal inglês apreende o homem como sendo capaz de se distanciar de seus interesses imediatos e de submetê-los à apreciação moral. Deduz-se, deste entendimento, que o homem possui a aptidão de se colocar no lugar do outro, sentimento originador das regras comuns, viabilizadora da convivência coletiva, ou seja, da materialização do sentimento de justiça. Um entendimento que se opõe fortemente a ideia do homem de que tem o seu 
comportamento orientado tão-somente pelo cálculo racional direcionado para a produção exclusiva do seu bem-estar, um ser afastado do saber cultural e moral.

Portanto, a análise econômica, mediada pela estrutura conceitual de Smith, também comporta as considerações essencialmente morais. Isto porque as escolhas econômicas atrelam-se aos sentimentos morais positivos, ou seja, a compaixão, o auxílio e a solidariedade. Sen (1992) se confronta com o que ele denomina de positivismo na economia e afirma que esta ciência seria bem mais profícua se trouxesse para suas análises as considerações éticas orientadoras do comportamento humano. Para este autor, a dimensão humana não comporta o olhar reducionista que define o homem como preso a uma única esfera de motivação, o interesse pessoal. Por isto, embora assente com a ideia de que a economia de mercado se trata de uma esfera legítima da livre produção e da distribuição, como assevera Grosjean (2000), Amarthya Sen não confunde "valor econômico" com os "valores humanos", embora estes últimos possam também ser promovidos pela atividade econômica.

Com efeito, os indivíduos têm suas escolhas mediadas por suas posições na estrutura social, ou seja, a casta, a classe social ou a profissão. Algumas escolhas feitas pelas pessoas são orientadas pelos consensos dos grupos formadores de uma situação social à qual o indivíduo pertence. Neste sentido, uma ação pode ser desenvolvida no intuito de atender determinações da posição social em que o indivíduo se encontra inserido e não necessariamente a um desejo pessoal; mas a observação de outro indivíduo, pertencente a outros grupos e inserido noutra situação social, pode enxergar na mesma ação uma vontade de atender interesses particulares.

Para Amarthya Sen, a liberdade se constitui de uma faceta positiva, concernente a todas as questões que uma pessoa é capaz ou incapaz de realizar; e de outra negativa, que se trata da inexistência de entraves à liberdade. Dubois e Mahieu (2009) afirmam que o economista indiano se inspirou na tipologia de liberdade elaborada pelo filósofo Berlin, e descrevem-nas nos seguintes termos: a liberdade positiva resulta do desejo de um indivíduo que se propõe protagonista de si mesmo, que elabora e constrói sua trajetória de vida; enquanto a liberdade negativa, trata-se da liberdade que se dá a partir do contrato que planeja o espaço em que os indivíduos podem agir sem impedimentos ocasionados por outros ou por instituições. 
Adotando exemplo do próprio Sen, têm-se que uma pessoa com deficiência motora que não pode passear num parque possui sua liberdade positiva limitada; enquanto a pessoa que não o faz por medo de ser agredido por marginais, tem sua liberdade negativa violada. O primeiro, para realizar sua liberdade positiva, precisa que lhe sejam ofertados meios que lhe permitissem superar as limitações para o exercício de sua liberdade positiva; o segundo, por sua vez, porta a necessidade de que o Estado impeça a violação de sua liberdade negativa. Deriva-se desta proposição analítica, que enxerga a liberdade condicionada a duas perspectivas, que, em princípio, o indivíduo possui a necessidade de que determinados meios sejam postos à sua disposição, pois sua liberdade pode ser obstada tanto por imposições advindas de sua condição humana como pela dinâmica da coletividade.

Por outro lado, os desejos dos indivíduos são construídos a partir da moral elaborada pelo ambiente cultural que os envolvem. Amarthya Sen demonstra a fortaleza desta influência sobre os indivíduos ao confrontar os anseios de igualdade, em relação aos homens, das mulheres norte-americanas e europeias com as mulheres indianas do ambiente rural. Ele afirma que estas últimas, grosso modo, não desejam conquistar a mesma posição social dos homens e nem se enxergam numa condição social penosa.

Diante desta constatação, o autor questiona: pode-se afirmar, então, que tais mulheres são realmente menos livres que os homens? Ele responde dizendo que não se pode concluir que elas almejem liberdade menor ou igual aos homens. Isto porque as liberdades das europeias e norte-americanas não se encontram nos horizontes das mulheres indianas ruralistas, que desconhecem as conquistas materiais e existenciais vividas pelas primeiras. Numa palavra, não se pode escolher aquilo que lhe é completamente desconhecido.

Outrossim, diz o economista indiano que também os analfabetos imersos no mundo rural de seu país não se lamentam de sua condição. Porém, chama a atenção para o fato de que se está diante de algo que indica falta de liberdade, pois o obstáculo a leitura se reproduz como uma multiplicidade de outras supressões de liberdades vinculadas à comunicação escrita. Defende Sen que a superação desta condição depende bem mais de ações direcionadas ao aumento das capacidades das pessoas do que da distribuição dos bens primários. 
Pode-se dizer, então, que se faz necessária, para além da distribuição dos bens primários, a execução de ações que permitam aos indivíduos aumentarem suas capacidades, o que implicaria dotá-los de liberdade para conquistar as coisas desejadas, portanto, de levá-los a se tornarem empreendedores de seus desejos particulares, de se tornarem por si sós os descobridores de novas possibilidades, de inventarem fórmulas para seus sustentos. Entrementes, para que estas possibilidades se tornem factíveis, é preciso que os indivíduos sejam dotados de mecanismos, que os levem a auto emancipação, ofertados por um Estado democrático. Ao asseverar esta estratégia de autonomização dos indivíduos, Amarthya Sen (2010) se apoia na ideia de que os bens primários são os meios exclusivos e capazes de tornar os indivíduos livres, ou seja, livres para acessar renda, realizar riqueza, usufruir das liberdades públicas.

Mas quais são as capacidades dos indivíduos que, estimuladas, podem conduzi-los à efetivação de suas liberdades efetivas? A realidade possui inumeráveis especificidades que tornam a distribuição igual de bens incapaz de gerar níveis iguais de liberdade. Como exemplifica Sen, algumas pessoas enfermas podem se encontrar impedidas de empreender formas de realizar seu bem-estar, como podem estar limitadas na participação do jogo político público, assim encontrando-se fora das decisões coletivas. Para o autor, somente uma ação concreta do Estado no sentido de corrigir distorções pode, por exemplo, tornar uma mãe solteira, imigrante, doente e no desemprego, habilitada para se confrontar numa assembleia política de cidadãos, em que participam majoritariamente homens brancos, qualificados, bem remunerados e capazes de argumentação lógica. Neste sentido, o economista indiano defende que é preciso tanto uma redistribuição das rendas como a estimulação das capacidades pessoais para que o indivíduo possa escolher o estilo de vida que lhe seja prazeroso. (SEN, 2010)

Em suma, a capacidade das pessoas está relacionada às questões de ordem pessoal e ao modelo de organização social. Daí a importância do Estado para o desenvolvimento das capacidades dos indivíduos. Assim, pode-se afirmar que a melhor organização social seria a mais apta à promoção das capacidades de uma coletividade específica, considerando que esta ação é fundamental para a efetivação das liberdades individuais. Neste entendimento é que Sen (2010) ancora sua compreensão de que a pobreza tem que ser enfrentada conjuntamente por ações que supram a falta de recursos e de bens primários, 
simultaneamente, às ações de fomento à dotação de liberdades viabilizadoras de uma vida digna.

A promoção do desenvolvimento das capacidades dos indivíduos trata-se, como explicita Bonvin (2005), de dotá-los do poder de converter os bens primários disponíveis em meios de aceder à condição de vida almejada, meios estes que podem ser recursos cognitivos ou materiais colocados ao alcance dos indivíduos pelo Estado; bem como o meio social, configurado também pelo poder público. Sen (2010) demonstra como estes fatores influem na condição de vida das pessoas por intermédio da comparação da taxa de mortalidade do segmento populacional de homens negros. Segundo o autor, no grupo etário de 25 a 45 anos, os homens negros têm uma taxa de mortalidade que chega a ser três vezes mais elevada que a dos homens brancos. Mas este fenômeno não se explica somente pelo desnível de renda, pois, ao se comparar os residentes do bairro negro do Harlem, em New York, com os residentes de Bangladesh, vê-se que os primeiros têm menos chance de alcançar os quarenta anos de idade, apesar de deterem renda mais elevada. A explicação, neste caso, demanda variáveis outras que não a renda, como capacidades não desenvolvidas, falta de autoestima e desesperança.

Amarthya Sen procede ainda uma distinção entre liberdades substanciais e liberdades instrumentais. Entende por liberdades substanciais o potencial existente no espaço público e que são disponibilizados e podem ser acionados contratualmente pelos membros da sociedade. Enquanto por liberdades instrumentais compreende-se o conjunto dos meios colocados à disposição da coletividade pelo poder público, que funcionam como viabilizadores da dinamização das liberdades substanciais. Têm-se uma combinação que possibilita que os bens primários sejam potencializados em ação, assim reforçando a capacidade dos indivíduos. Defende o autor que tais condições geram um círculo virtuoso viabilizado pelo jogo democrático, que se assenta na capacidade de se criticar o poder das instituições públicas responsáveis por engendrar as liberdades instrumentais que tencionam a ampliação das capacidades individuais.

Alicerçado nesta ideia, defende, sobremaneira, Amarthya Sen (2010) a importância de uma imprensa livre a existência de meios plurais de informação, que, segundo o autor, funcionam como fatores de sensibilização política e, por decorrência, como formas de assegurar a estabilidade econômica. Chama a atenção ainda para o fato de que a fome existente no mundo contemporâneo, ao chegar ao conhecimento amplo da comunidade, 
provocam indignação, assim gerando ondas de pressão sobre os governos. Sen esclarece que isto ocorre porque os homens não são indiferentes às desgraças que se abatem sobre seus semelhantes. Compara, então, as privações fundamentais da Índia com a China maoísta; segundo o economista indiano, após a independência de seu país de origem não se assistiu mais aos eventos que levavam milhares a morte por fome, como se verificavam na Índia sob dominação inglesa. A democracia aí instaurada, em que pontilham uma imprensa relativamente independente, eleições permanentes e uma oposição atuante, conduziu o governo indiano a vivenciar o que é comum nas sociedades democráticas, reação popular quando a gestão governamental é relapsa na adoção de ações preventivas de combate à fome.

Esclarece ainda Sen (2010) que a China, no período de 1958 a 1961, foi palco de uma mortandade estimada em 30 milhões de pessoas sem que houvesse inflexão nas políticas governamentais desastrosas. Fato este que foi possível pela ausência plena de elementos democráticos no sistema político chinês, de sorte que as condições geradoras da fome mortal não foram questionadas. Não recaiu, sobre o governo Chinês, ameaças e nem denúncias, pois a imprensa sob controle estatal manteve-se inerte diante do extermínio. Em oposição a este registro histórico, o economista salienta que onde prevalece uma imprensa livre e uma oposição política atuante à ação governamental tende a debelar o fenômeno antes de seu recrudescimento, portanto, antes de se tornar em morticínio generalizado. Veem-se aí os benefícios da ação dos indivíduos quando livres de constrangimento, que põe em marcha as liberdades negativas e as liberdades positivas, que permitem que se faça aquilo que é moralmente legítimo e que se deseja realizado, dado que se está livre para realizar e se dispõe dos meios e dos instrumentos necessários.

A ideia de liberdade e da capacidade como elementos essenciais para o desenvolvimento da pessoa demonstra-se no exemplo dos deficientes auditivos, que embora desimpedidos de assistir aos concertos não comparecem efetivamente dada suas limitações físicas, mas que se sentirão confortáveis para fazê-lo se tiverem acesso às próteses auditivas. Neste sentido, pode-se afirmar que procede o pensamento que enxerga na inserção profissional uma ação que extrapola a mera aquisição de habilidades para o trabalho, uma vez que conduz as pessoas a se sentirem confiantes em si mesmos, de se reconhecerem como seres produtivos e criativos. 
Observa-se no pensamento de Amarthya Sen a proposição de um Estado social ativo, uma vez que se deriva de suas reflexões que ele defende a adoção de ações estatais orientadas para a redução das desigualdades de renda, bem como propugna a ampliação e o aperfeiçoamento dos serviços públicos. Além do que, está posto como fundamental para o desenvolvimento das pessoas a capacitação que, em última instância, resulta no aumento da produtividade a partir de investimentos sociais, ou seja, na educação e na formação do indivíduo. Em suma, é mister que se capacitem os atores sociais para que eles possam transformar os meios em condições de realizar seu bem-estar, meios estes que são intelectuais, culturais e sociais. Como enfatiza Sen (2010, p. 191), "há evidências de que, mesmo com renda relativamente baixa, um país que garante serviços de saúde e educação a todos pode efetivamente obter resultados notáveis da duração e qualidade de vida de toda a população."

\section{Para concluir: liberdade, felicidade e Estado de bem-estar social}

A liberdade aparece no pensamento de Hobbes como condicionada à inexistência de obstáculos externos às ações que objetivam a preservação da vida. O filósofo apreende o homem como estando numa busca permanente para a aquisição de poder, ou seja, dos meios que lhe permitem conquistar as coisas idealizadas como objetos que lhe proporcionará prazer. Neste entendimento, assenta-se o princípio de progresso contínuo, isto ocorre porque não se busca uma satisfação somente para o aqui e agora, mas uma satisfação que se reproduza no futuro, assim o homem está fadado a procurar sempre a acumulação crescente dos meios geradores de poder. Com efeito, o homem é livre quando pode colocar em marcha sua força ou inteligência para alcançar os bens que deseja, portanto, que não haja impedimentos à sua vontade e ao exercício de suas capacidades para realizar o que deseja.

Esta acumulação de meios que assegura poder é o que permite ao homem, em primeira instância, a garantia de sua existência mesma, bem como o seu bem-estar no presente e no futuro, mas principalmente lhe possibilita desvencilhar-se da ameaça de outros que intentem contra os meios acumulados que lhe garantem sua vida e mesmo contra a própria vida. Vê-se, então, que, para Hobbes, a liberdade se trata de um direito de agir consoante aos desejos; entretanto, como o que é desejado é aquilo que é útil, a ação do homem se fundamenta na necessidade. Neste sentido, como assevera Maruyama (2009), 
enquanto direito natural, inexistindo algum poder exterior, pode-se afirmar que a liberdade se trata de fazer algo sem a ocorrência de constrangimentos.

Têm-se aí o entendimento de que o direito natural, ou liberdade, possibilita o uso do poder adquirido para salvaguardar a própria vida, mesmo que daí decorra a investidura contra a vida de outrem. Portanto, Hobbes entende a liberdade como princípio de conservação da existência, o que leva a uma vinculação relacional do plano jurídico com o plano biológico. Neste sentido, deixado livre, sem constrangimentos externos, o direito natural em absoluta liberdade implicaria numa condição de vida que levaria "a guerra de todos contra todos”. Assim, a remoção das leis acarreta na liberdade absoluta, portanto, a liberdade na sua perspectiva negativa se concretiza no direito positivado.

Enfim, no pensamento de Hobbes, o direito natural emerge como aquilo que escapa ao conjunto normativo, trata-se, então, do que não está positivado. Embora uma sociabilidade destituída de leis e regida pela relação de poder individual não seja capaz de originar direito, em Hobbes está dado a possibilidade da convenção, que cerceia a liberdade absoluta, ou seja, o uso pleno do poder para alcançar tudo aquilo que permite a conservação da vida. A renúncia a este direito, por convenção, é o que fundamenta o poder político; em síntese, uma ação dos homens que pode ser traduzida como o reconhecimento de que todos têm o mesmo direito que um indivíduo pensa para si.

As ideias de Amarthya Sen, explicitadas principalmente na obra Desenvolvimento com liberdade, remete para o entendimento de que o crescimento da renda por pessoa não é suficiente para a realização do desenvolvimento humano, e nem mesmo a distribuição equitativa da renda. Isto porque o autor acredita que o desenvolvimento se trata de um processo que resulta do crescimento das liberdades reais dos indivíduos. Neste sentido, é a conquista das liberdades políticas, sociais e econômicas que possibilitam uma organização social em que cada pessoa pode ser o protagonista da formulação, da realização e do gozo de seus valores.

Esta abordagem inovadora idealiza que cada pessoa deve perquirir uma felicidade do tipo multidimensional, simultaneamente constituída de liberdades individuais e coletivas. A liberdade se trata de um elemento fundamental da condição humana devido ao fato de ser um elemento capaz de dotar cada um de contribuir consigo mesmo para o próprio desenvolvimento. Justamente por isto, Amarthya Sen defende que o que importa é a liberdade de poder conquistar mais liberdade. 
É preciso ainda que as liberdades almejadas estejam distribuídas em vários domínios, por exemplo, a liberdade de não morrer de inanição, de auferir renda que lhe permita o acesso aos bens necessários, aos serviços de saúde, à educação e à cultura, de poder exercer a espiritualidade de sua escolha etc. Como as liberdades a serem conquistadas constituem um amplo espectro, é de certa forma esperado que as ações de desenvolvimento se deem a partir de lutas contra os obstáculos interpostos para a realização das liberdades nos campos político, econômico e social, principalmente quando tais liberdades possibilitam igualdades de oportunidades, de proteção e de segurança.

É ainda vital que os esforços sejam realizados para que de fato se produza liberdade em vários domínios, de tal maneira que se crie uma sinergia em que as liberdades se reforcem umas às outras. A liberdade política é destituída de substância sem que haja liberdades para empreender e para empregar a renda; trata-se também de uma liberdade vazia de conteúdo se não for complementada com a liberdade de se poder recorrer à justiça. Por outro lado, a liberdade de se associar, de se expressar, de criticar e de poder atuar para o funcionamento do sistema de governo é fundamental para o estabelecimento dos valores socialmente necessários e reivindicados pela coletividade. Assim, Amarthya Sen compreende que o desenvolvimento é um fenômeno que resulta de ações desprendidas para tornar todas as liberdades reais e sempre mais amplas; considerando, sobretudo, que tal esforço deve começar pelas liberdades que são mais ultrajadas.

O bem-estar social pode ser compreendido como um estado em que os meios compreendidos pela coletividade como viabilizadores da felicidade se encontram ao alcance de todos. Em Hobbes, a felicidade está no fato de que o homem pode empreender esforços para acumular os meios que lhe garante poder, ou seja, que possa num movimento permanente e sem constrangimentos conquistar os bens materiais e os imateriais viabilizadores do bem-estar no presente e no futuro. Entretanto, todos devem ter direito a se exercitar no sentido desta conquista, assim como igual direito de não ter aquilo que foi conquistado ameaçado pelo desejo de outros. Neste sentido, por convenção, a instituição de um poder superior ao de todos os poderes individuais - o Estado - se faz necessária para impedir a emergência de tal ameaça e, portanto, garantir a liberdade da ação de cada um para entabular estratégias que lhe permita o acesso às coisas percebidas como prazerosas, geradoras de felicidade. Em Amarthya Sen, a felicidade se encontra na liberdade de poder escolher aos bens imaginados como capazes de proporcionar felicidade, o que significa ser 
capaz de promover o desenvolvimento de si mesmo. Para tanto, faz-se necessário a ausência de obstáculos, sejam interiores ou indivíduo ou exteriores, de sorte que o Estado propugnado por Sen deve funcionar no sentido de realizar as garantias mínimas de uma vida digna e a capacitação de todos para a autonomia de serem protagonistas de suas trajetórias de vida.

\section{Referências}

ARRUDA, Gerardo Clésio Maia e TEIXEIRA, Zaneir Gonçalves. Origem e controle da violência: uma discussão a partir dos pensamentos de Thomas Hobbes e Sigmund Freud. In: BASSO, Ana Paula; CADEMARTORI, Daniela Mesquita Leutchuk e RAMOS, Marcelo Maciel. Sociologia, antropologia e cultura jurídica. Florianópolis: CONPEDI, 2015.

BONVIN, Jean-Michel. La démocratie dans l'approche d'Amartya Sen. L'Économie politique, vol. $\mathrm{n}^{\mathrm{o}} 27$, no. 3, 2005, pp. 24-37.

CAILLÉ, Alain et all. História argumentada da filosofia moral e política. São Leopoldo: Editora UNISINOS, 2004.

DOCKÈS, Pierre. Hobbes et le pouvoir. Cahiers d'économie politique / Papers in Political Economy, vol. 50, no. 1, 2006, pp. 7-25.

DUBOIS, Jean-Luc e MAHIEU, François-Régis. Sen, liberte et pratiques du développement. Revue Tiers Monde, vol. 198, no. 2, 2009, pp. 245-261.

FOISNEAU, Luc. Hobbes: os fundamentos da teoria da felicidade. In: CAILLÉ, Alain et all. História argumentada da filosofia moral e política. São Leopoldo: Editora UNISINOS, 2004.

GROSJEAN, Paul. La pensée d'Amarthya Sen sur le développement. Revue Quart Monde. No. 176, 2000, pp. 01-13.

HOBBES, Thomas. Levitã ou matéria, forma e poder de um Estado eclesiástico e civil. (Coleção Os Pensadores). São Paulo: Abril Cultural, 1979.

MARX, Karl. O capital. São Paulo: Editora Bertrand Brasil - DIFEL, 1987.

MURUYAMA, Natalia. Liberdade, lei natural e direito natural em Hobbes: limiar do direito e da política na modernidade. São Paulo: Revista Trans/Form/Ação, No. 32, 2009, pp. $45-62$

REALE, Giovanni e ANTISERI, Dario. História da filosofia: de Spinoza a Kant. São Paulo: Paulus, 2005. 
RUSSEL, Bertrand. História da filosofia ocidental. (Tradução de Breno Silveira). $3^{\text {a }}$ Edição. São Paulo: Companhia Editora Nacional, 1969.

SEN, Amarthya. Comportamento econômico e sentimentos morais. São Paulo: Lua Nova: Revista de Cultura e Política, No. 25, abril, 1992, pp. 01-15.

2010.

Desenvolvimento como liberdade. São Paulo: Companhia das Letras,

SMITH, Adam. Riqueza das nações. São Paulo: Hemus editora Ltda, 1981.

STORK, Ricardo Yepes e ECHEVARRÍA, Javier Aranguren. Fundamentos de antropologia: um ideal de excelência humana. São Paulo: Instituto Brasileiro de Filosofia e Ciência, 2005. 